Pacific Journal of Mathematic 


\title{
A NOTE ON PSEUDO-CREATIVE SETS AND CYLINDERS
}

\author{
PAUL R. Young
}

1. Notation and Definitions. We will use $N$ to denote the set of all nonnegative integers. Unless specifically mentioned otherwise, all sets are considered subsets of $N$. If $A$ is a set, $A^{\prime}=N-A$. Since we consider only sets of nonnegative integers, we will not use Cartesian products of sets but will instead work with images of Cartesian products under some effective mapping. More specifically, if $A$ and $B$ are sets, let $A \otimes B=\{(a, b) \mid a \in A$ and $b \in B\}$. Let $\tau$ be any one-to-one effective mapping of $N \otimes N$ onto $N$. Then we define $A \times B$ to be $\tau(A \otimes B)$, and we abbreviate $\tau((a, b))$ to $\langle a, b\rangle$. (This is the notation introduced by Rogers in [4].) Given integers $a$ and $b$ we can always effectively find the integer $\langle a, b\rangle$, and given the integer $\langle a, b\rangle$ we can always effectively find $a$ and $b$.

In [2], Myhill has called a set a cylinder if it is recursively isomorphic to $B \times N$ for some r.e. set $B$; however we will follow Rogers in calling a set, $A$, a cylinder if it is recursively isomorphic to $B \times N$ for any set $B$. Such a set $A$ is called a cylinder of $B$.

For definitions of recursive, simple, and creative sets, see [3]. A noncreative, recursively enumerable (r.e.), set $A$ has been called pseudocreative if for every r.e. set $B \subset A^{\prime}$ there is an infinite r.e. set $C \subset A^{\prime}$ such that $B \cap C=\varnothing$. A nonrecursive r.e. set $A$ has been called pseudo-simple if there is an infinite r.e. set $B \subset A^{\prime}$ such that $A \cup B$ is simple. We will denote the class of all recursive sets by $\mathscr{C}_{0}$, the class of all simple sets by $\mathscr{C}_{1}$, the class of all pseudo-simple sets by $\mathscr{C}_{2}$, the class of all pseudo-creative sets by $\mathscr{C}_{3}$, and the class of all creative sets by $\mathscr{C}_{4}$. These classes are pairwise disjoint and every r.e. set falls into one of the classes ([2]).

Let $A$ and $B$ be sets. We write $A \leqq_{1} B$ if there is a one-to-one recursive function such that $x \in A$ if and only if $f(x) \in B, A \leqq_{m} B$ if there is some recursive function $g$ such that $x \in A$ if and only if $g(x) \in B$, and $A \leqq_{b t t} B$ if $A$ is reducible to $B$ via bounded truth-tables. If there is no recursive function $g$ such that $x \in A$ if and only if $g(x) \in B$, we write $A \varliminf_{m} B$. If both $A \leqq_{m} B$ and $B \leqq_{m} A$, we write $A \equiv_{m} B$.

2. Introduction and preliminaries. In [2] it is shown that the class of pseudo-creative sets is nonempty by proving that the cylinder of any nonrecursive, noncreative, r.e. set is pseudo-creative. In this

Received June 28, 1963. Supported by National Science Foundation Fellowships. The results reported here are a portion of the author's doctoral dissertation written at M.I.T. under the direction of Prof. Hartley Rogers, Jr. 
note we shall show that there is a pseudo-creative set which is not a cylinder, and we shall develop some related facts concerning the relation between pseudo-creative sets and cylinders.

LEMma 1 (Myhill). Every creative set is a cylinder. Every recursive set which is infinite and has an infinite complement is a cylinder. The empty set and $N$ are cylinders. If $A$ is pseudo-creative, pseudo-simple, or simple, then any cylinder of $A$ is pseudo-creative. No simple set or pseudo-simple set is a cylinder. If $A$ is r.e., then $A \leqq_{1} A \times N$ and $A \times N \leqq_{m} A$.

Proof. The proofs are straightforward and may be found in [2]. The requirement in the last assertion that $A$ be r.e. may be omitted.

Lemma 2. Let $A$ be a cylinder. Then there exists a one-to-one recursive function $f$ such that $x \in A$ implies that $\left\{x, f(x), f^{2}(x), f^{3}(x), \cdots\right\}$ is an infinite r.e. subset of $A$, and $x \in A^{\prime}$ implies that $\left\{x, f(x), f^{2}(x)\right.$, $\left.f^{3}(x), \cdots\right\}$ is an infinite r.e. subset of $A^{\prime}$.

Proof. We may assume $A=B \times N$ for some set $B$. Define $f(\langle x, n\rangle)=\langle x, n+1\rangle$.

Lemma 3 (Post-Shoenfield). If $B$ is a r.e. set and if $A \leqq_{b t t} B$ where $A$ is creative, then $B$ is either creative or pseudo-creative.

Proof. In [3] it is shown that $B$ cannot be recursive or simple. In [5] it is shown that $B$ cannot be pseudo-simple.

Lemma 4. Let $A \in \mathscr{C}_{i}, B \in \mathscr{C}_{j}$, and $A \leqq_{1} B$. Then $i \leqq j$.

Proof. The proof follows easily from the definitions and will be omitted.

Lemma 5 (Fischer). There is a simple set $S$ such that $S \times S \not_{m} S$.

Proof. See [1].

3. Results. An infinite set which contains no infinite r.e. subset is called immune ([3]).

Lemma 6. If $A$ is a nonimmune infinite set, then $A \times N \leqq_{1} A \times A$.

Proof. Let $B$ be an infinite r.e. subset of $A$ and let $g$ be a oneto-one recursive function whose range is $B$. Define $h(\langle a, b\rangle)=\langle a, g(b)\rangle$. 
Then $h$ is a one-to-one recursive function and $x \in A \times N$ if and only if $h(x) \in A \times A$.

CoRollary 1. Suppose $S$ is simple or pseudo-simple. Then $S \times S$ is pseudo-creative.

Proof. By Lemma 6, $S \times N \leqq_{1} S \times S$. By Lemma $1 S \times N$ is pseudo-creative and therefore by Lemma $4 S \times S$ is either pseudo-creative or creative. Since $S \times S \leqq_{b t t} S$, by Lemma $3 S \times S$ cannot be creative.

Theorem 1. Let $A$ be an infinite nonimmune set. Then $A \times A \leqq_{m} A$ implies that $A \times A$ is a cylinder.

Proof. Suppose $A \times A \leqq_{m} A$ via the recursive function $g$. Define $h(\langle a, b\rangle)=\langle g(\langle a, b\rangle),\langle a, b\rangle\rangle$. Then $A \times A \leqq_{1} A \times N$ via $h$. By Lemma 6 , $A \times N \leqq_{1} A \times A$. Thus $A \times A$ is recursively isomorphic to $A \times N$.

THEOREM 2. Let $A$ be any infinite r.e. set which is not pseudocreative. Then $A \times A \leqq_{m} A$ if and only if $A \times A$ is a cylinder.

Proof. In view of the preceding theorem, we need only prove that if $A \times A$ is a cylinder then $A \times A \leqq_{m} A$.

If $A$ is creative or recursive so is $A \times A$, and in this case $A \times A \equiv_{m} A$ and $A \times A$ is a cylinder. Therefore we may assume that $A$ is simple or pseudo-simple. Let $B \subset A^{\prime}$ be a r.e. set such that $A \cup B$ is simple. (If $A$ is simple, $B$ is finite.) Let $B_{0}=A \times N \cup N \times B$, and let $B_{1}=N \times A \cup B \times N . \quad B_{0} \cup B_{1}$ is simple, for otherwise there is an infinite r.e. set $C \subset B_{0}^{\prime} \cap B_{1}^{\prime}$, and this implies that either $\{x \mid(\exists y)[\langle x, y\rangle \in C]\}$ is an infinite r.e. subset of $A^{\prime} \cap B^{\prime}$ or $\{y \mid(\exists x)[\langle x, y\rangle \in C]\}$ is an infinite r.e. subset of $A^{\prime} \cap B^{\prime}$.

Assume $A \times A$ is a cylinder and let $f$ be the recursive function described in Lemma 2. (So $x \in A \times A$ implies that $\left\{x, f(x), f^{2}(x), \cdots\right\}$ is an infinite r.e. subset of $A \times A$ and $x \in(A \times A)^{\prime}$ implies that $\left\{x, f(x), f^{2}(x), \cdots\right\}$ is an infinite subset of $(A \times A)^{\prime}$.)

To obtain a many-one reduction of $A \times A$ to $A$ : Given $x$, enumerate $\left\{x, f(x), f^{2}(x), f^{3}(x), \cdots\right\}, B_{0}$, and $B_{1}$. Since $B_{0} \cup B_{1}$ is simple, we must eventually find an integer $\langle c, d\rangle$ either in $\left\{x, f(x), f^{2}(x), \cdots\right\} \cap B_{0}$ or in $\left\{x, f(x), f^{2}(x), \cdots\right\} \cap B_{1}$. In the former case define $g(x)=d$; in the latter case define $g(x)=c$. Then $x \in A \times A$ if and only if $g(x) \in A$.

We next modify Theorem 2 to characterize a class of pseudo-creative noncylinders.

Corollary 2. Let $A$ be a r.e. set which is not pseudo-creative. Then $A \times A$ is a pseudo-creative noncylinder if and only if $A \times A \not_{m} A$. 
Proof. If $A$ is recursive, $A \times A$ is also recursive and $A \times A$ is many-one equivalent to $A$. If $A$ is creative, since $A \leqq_{1} A \times N \leqq{ }_{1} A \times A$, $A \times A$ is also creative and hence many-one equivalent to $A$. The corollary now follows from Theorem 2 and Corollary 1.

COROLLARY 3. There exists a pseudo-creative set which is not a cylinder and which is bounded-truth-table reducible to a simple set.

Proof. By Lemma 5 there is a simple set $S$ such that $S \times S \not \bigsqcup_{m} S$. Since $S \times S \leqq_{b t t} S, S \times S$ is the desired set.

Our next theorem shows that Theorem 2 cannot be strengthened to include the pseudo-creative sets.

THEOREM 3. There is a pseudo-creative set $A$ such that $A \times A$ is a cylinder but $A \times A \not 士_{m} A$.

Proof. Let $S$ be a simple set such that $S \times S \not_{m} S$. Then

$$
S \equiv_{m} S \times N \leqq_{1} S \times S \leqq_{1}(S \times S) \times N \leqq_{1}(S \times N) \times(S \times N) .
$$

Let $A=S \times N$. Then $A \times A$ is clearly a cylinder, but $A \times A \leqq_{m} A$ implies that $S \times S \leqq_{m} S$, a contradiction. Thus $A \times A \varliminf_{m} A$, and by either Lemma 1 or Theorem $2, A$ is pseudo-creative.

Since any set is many-one equivalent to its cylinder and all creative sets are many-one equivalent, the cylinder of any pseudo-creative set is still pseudo-creative. Thus, since any set is one-to-one reducible to its cylinder, we might hope to subclassify the pseudo-creative sets into cylinders and noncylinders and obtain for the subclassification a result analogous to Lemma 4. In view of the following theorem, such an analogue fails.

THEOREM 4. There exist pseudo-creative sets $A$ and $B$ such that $A$ is a cylinder and $A \leqq_{1} B$, but $B$ is not a cylinder.

Proof. Let $A=S \times N$ and $B=S \times S$ where $S$ is a simple set such that $S \times S \not_{m} S$. By Theorem $2, S \times S$ is not a cylinder, and by Lemma $6, A \leqq_{1} B$. By Lemma $1 A$ is pseudo-creative, and by Corollary $1, B$ is pseudo-creative.

REMARKS. 1. In another paper we shall show that there is a pseudo-creative set which is not a cylinder and which, in contrast to those pseudo-creative noncylinders constructed by using Theorem 2, is not bounded-truth-table reducible either to a simple set or to a pseudo-simple set.

2. The author does not know if there is a simple, pseudo-simple, 
or pseudo-creative set $A$ such that $A \times A \leqq_{m} A$. The question of whether such a set exists is equivalent to the following question: Is it true that if $A$ is a r.e. set, then $A \times A \$_{m} A$ if and only if $A$ is either recursive or creative?

\section{REFERENCES}

1. P. Fischer, $A$ note on bounded-truth-table reducibility, Proc. Amer. Math. Soc., 14 (1963), 875-877.

2. J. Myhill, Recursive digraphs, splinters and cylinders, Math. Annalen, 133 (1959), 211-218.

3. E. L. Post, Recursively enumerable sets of positive integers and their decision problems, Bull. Amer. Math. Soc., 50 (1944), 284-316.

4. H. Rogers, Jr., Recursive functions and effective computability, To be published by McGraw Hill.

5. J. Shoenfield, Quasicreative sets, Proc. Amer. Math. Soc., 8 (1957), 964-967.

REed COLLEGE 



\title{
PACIFIC JOURNAL OF MATHEMATICS
}

\author{
EDITORS
}

\author{
Robert Osserman \\ Stanford University \\ Stanford, California \\ M. G. Arsove \\ University of Washington \\ Seattle 5, Washington
}

\author{
J. Dugundji \\ University of Southern California \\ Los Angeles 7, California \\ Lowell J. Paige \\ University of California \\ Los Angeles 24, California
}

\section{ASSOCIATE EDITORS}
E. F. BECKENBACH
B. H. NEUMANN
F. WOLF
K. YOSHIDA

\section{SUPPORTING INSTITUTIONS}

\author{
UNIVERSITY OF BRITISH COLUMBIA \\ CALIFORNIA INSTITUTE OF TECHNOLOGY \\ UNIVERSITY OF CALIFORNIA \\ MONTANA STATE UNIVERSITY \\ UNIVERSITY OF NEVADA \\ NEW MEXICO STATE UNIVERSITY \\ OREGON STATE UNIVERSITY \\ UNIVERSITY OF OREGON \\ OSAKA UNIVERSITY \\ UNIVERSITY OF SOUTHERN CALIFORNIA
}

\author{
STANFORD UNIVERSITY \\ UNIVERSITY OF TOKYO \\ UNIVERSITY OF UTAH \\ WASHINGTON STATE UNIVERSITY \\ UNIVERSITY OF WASHINGTON \\ AMERICAN MATHEMATICAL SOCIETY \\ CALIFORNIA RESEARCH CORPORATION \\ SPACE TECHNOLOGY LABORATORIES \\ NAVAL ORDNANCE TEST STATION
}

Mathematical papers intended for publication in the Pacific Journal of Mathematics should by typewritten (double spaced), and on submission, must be accompanied by a separate author's résumé. Manuscripts may be sent to any one of the four editors. All other communications to the editors should be addressed to the managing editor, L. J. Paige at the University of California, Los Angeles 24, California.

50 reprints per author of each article are furnished free of charge; additional copies may be obtained at cost in multiples of 50 .

The Pacific Journal of Mathematics is published quarterly, in March, June, September, and December. Effective with Volume 13 the price per volume (4 numbers) is $\$ 18.00$; single issues, $\$ 5.00$. Special price for current issues to individual faculty members of supporting institutions and to individual members of the American Mathematical Society: $\$ 8.00$ per volume; single issues $\$ 2.50$. Back numbers are available.

Subscriptions, orders for back numbers, and changes of address should be sent to Pacific Journal of Mathematics, 103 Highland Boulevard, Berkeley 8, California.

Printed at Kokusai Bunken Insatsusha (International Academic Printing Co., Ltd.), No. 6, 2-chome, Fujimi-cho, Chiyoda-ku, Tokyo, Japan.

PUBLISHED BY PACIFIC JOURNAL OF MATHEMATICS, A NON-PROFIT CORPORATION

The Supporting Institutions listed above contribute to the cost of publication of this Journal, but they are not owners or publishers and have no responsibility for its content or policies. 


\section{Pacific Journal of Mathematics}

\section{Vol. 14, No. $2 \quad$ June, 1964}

Tom M. (Mike) Apostol and Herbert S. Zuckerman, On the functional equation $F(m n) F((m, n))=F(m) F(n) f((m, n)) \ldots \ldots \ldots \ldots \ldots \ldots \ldots \ldots \ldots \ldots \ldots$

Reinhold Baer, Irreducible groups of automorphisms of abelian groups . . . . . . . 385

Herbert Stanley Bear, Jr., An abstract potential theory with continuous kernel . . . . 407

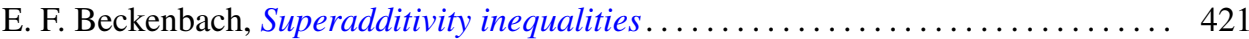

R. H. Bing, The simple connectivity of the sum of two disks . . . . . . . . . . . 439

Herbert Busemann, Length-preserving maps ...................... 457

Heron S. Collins, Characterizations of convolution semigroups of measures . . . . . . 479

Paul F. Conrad, The relationship between the radical of a lattice-ordered group and complete distributivity............................ 493

P. H. Doyle, III, A sufficient condition that an arc in $S^{n}$ be cellular . . . . . . . . . 501

Carl Clifton Faith and Yuzo Utumi, Intrinsic extensions of rings . . . . . . . . . . 505

Watson Bryan Fulks, An approximate Gauss mean value theorem . . . . . . . . . . 513

Arshag Berge Hajian, Strongly recurrent transformations . . . . . . . . . . . . . 517

Morisuke Hasumi and T. P. Srinivasan, Doubly invariant subspaces. II . . . . . . . 525

Lowell A. Hinrichs, Ivan Niven and Charles L. Vanden Eynden, Fields defined by

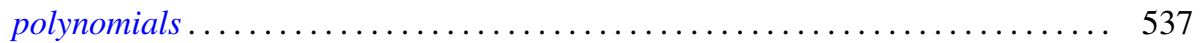

Walter Ball Laffer, I and Henry B. Mann, Decomposition of sets of group

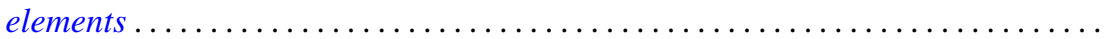

John Albert Lindberg, Jr., Algebraic extensions of commutative Banach

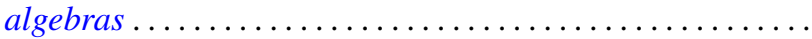

W. Ljunggren, On the Diophantine equation $C x^{2}+D=y^{n} \ldots$

M. Donald MacLaren, Atomic orthocomplemented lattices ....

Moshe Marcus, Transformations of domains in the plane and applications in the

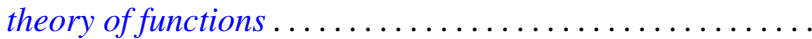

Philip Miles, $B^{*}$ algebra unit ball extremal points . .................. 627

W. F. Newns, On the difference and sum of a basic set of polynomials . . . . . . . 639

Barbara Osofsky, Rings all of whose finitely generated modules are injective ...... 645

Calvin R. Putnam, Toeplitz, matrices and invertibility of Hankel matrices . . . . . . . 651

Shoichiro Sakai, Weakly compact operators on operator algebras . . . . . . . . . 659

James E. Simpson, Nilpotency and spectral operators . . . . . . . . . . . . . 665

Walter Laws Smith, On the elementary renewal theorem for non-identically

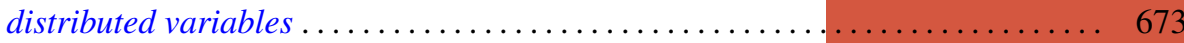

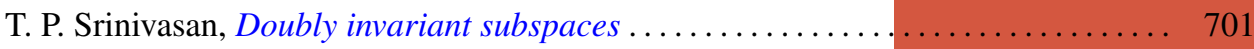

J. Roger Teller, On the extensions of lattice-ordered groups . . . . . . . . . . . . 709

Robert Charles Thompson, Unimodular group matrices with rational integers as

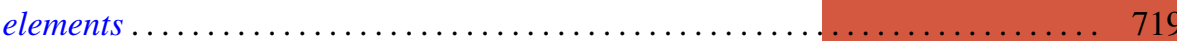

J. L. Walsh and Ambikeshwar Sharma, Least squares and interpolation in roots of unity

Charles Edward Watts, A Jordan-Hölder theorem .................... 731

Kung-Wei Yang, On some finite groups and their cohomology .............. 735

Adil Mohamed Yaqub, On the ring-logic character of certain rings ............ 741

Paul Ruel Young, A note on pseudo-creative sets and cylinders 